Bond University

Research Repository

\title{
Cross-cultural differences in personality, motivation and cognition in Asian vs. Western societies
}

Boyle, Gregory J.; Wongsri, Nongkran; Bahr, Mark; Macayan, Jonathan V.; Bentler, Peter M.

Published in:

Personality and Individual Differences

DOI:

10.1016/j.paid.2020.109834

Licence:

CC BY-NC-ND

Link to output in Bond University research repository.

Recommended citation(APA):

Boyle, G. J., Wongsri, N., Bahr, M., Macayan, J. V., \& Bentler, P. M. (2020). Cross-cultural differences in personality, motivation and cognition in Asian vs. Western societies. Personality and Individual Differences, 159, [109834]. https://doi.org/10.1016/j.paid.2020.109834

\section{General rights}

Copyright and moral rights for the publications made accessible in the public portal are retained by the authors and/or other copyright owners and it is a condition of accessing publications that users recognise and abide by the legal requirements associated with these rights.

For more information, or if you believe that this document breaches copyright, please contact the Bond University research repository coordinator 
Cross-cultural differences in personality, motivation and cognition in Asian vs. Western societies

\author{
Gregory J. Boyle
}

1. Centre for Positive Psychology, University of Melbourne, Parkville, VIC 3010, Australia

2. Bond University, Gold Coast, QLD 4229, Australia

\author{
Nongkran Wongsri
}

Saint Louis College, Bangkok 10120, Thailand

Mark Bahr

Bond University, Gold Coast, QLD 4229, Australia

\author{
Jonathan V. Macayan \\ Mapúa University, Manila 1001, Philippines \\ and \\ Peter M. Bentler \\ University of California, Los Angeles, CA 90095, USA
}




\section{Introduction}

Culture has been defined as "the integrated pattern of human knowledge, belief, and behaviour that depends upon the capacity for learning and transmitting knowledge to succeeding generations" (Fernandez 2010), encompassing traditions, languages, and belief systems that affect perception of the world. Culture, with its common assumptions, values, and behaviours, is the shared way of perceiving and thinking among members of a group/nation (Berry, Poortinga, Breugelmans, Chasiotis, \& Sam, 2011). Culture is a configuration of thoughts, feelings, and behaviours shared by group members which may impact on an individual's psychological well-being, goal orientation, motivation, and study approach (Manikutty, Anuradha, \& Hansen 2007). Culture shapes individuals' attitudes and motivation towards academic learning (Klassen et al., 2013).

Several studies have included culture as an explanatory variable (e.g., Chiu, Kim, \& Wan., 2008; Choi \& Kim, 2013; Kang \& Chang, 2016). Individual differences in personality, motivation and cognition (Saklofske \& Eysenck, 2004) are influenced by social learning in adapting to cultural environments (Chang et al., 2011; Chiu et al., 2008; Chiu, Chia, \& Wan, 2015; Stankov \& Lee, 2008; van de Vijver \& van Hemert, 2008). Wongsri (2004) found that culturally-shaped variables such as goal orientation, academic volitional strategies, depth of learning, and happiness/psychological wellbeing interact synergistically in impacting on academic learning (also see, Bernardo \& Liem, 2013; Hwang \& Matsumoto, 2013; Joy \& Kolb, 2009; Zhue, \& Leung, 2011). In the era of transnational education (Heffernan et al., 2010), it is germane to ask what is the role of cultural nuances in contributing to crosscultural differences in academic performance?

Goal orientation theory is a major social-cognitive theory of achievement motivation (Dela Rosa \& Bernardo, 2013; Macayan, 2012; Yeo, Loft, Xiao, \& Kiewitz 2009). In the 
Midgley et al. (1998) model, goal orientation is conceptualised as comprising: mastery (taskorientation), performance-approach, and performance-avoidance orientations (Macayan, 2012). While high task-oriented students value learning that is inherently meaningful, and high performance-approach oriented students seek favourable judgements from others, performance-avoidance oriented students try to minimise others' unfavourable judgements (Elliot, \& Murayama, 2008). Watson, Meade, Surface, \& van de Walle (2007) reported that goal orientation predicts academic self-efficacy, psychological wellbeing, and GPAs. Cultural conditioning clearly impacts on goal orientation and other predictors of learning (Dekker \& Fischer, 2008; Gao, Xiang, Harrison, Guan, \& Rao, 2008; King, 2016; Zhue \& Leung, 2011). Comparing cultures on achievement goals, using theoretical categorisation labels (e.g., individualistic vs. collectivistic; independent vs. interdependent - e.g., Yu \& Yang, 1994), Macayan (2012) provided evidence for the differential effects of cultural orientations (Asian vs. Western) on academic performance. Previously, the varying impacts of mastery and performance (approach and avoidance goal orientations) on academic achievement had been reported (e.g., Salili, Chiu, \& Lai, 2001). Achievement goals, mastery and performance orientation correlate positively in several Asian studies (Bernardo, 2003; Chang \& Wong, 2008; Ho \& Hau, 2008; Lau \& Lee, 2008), contradicting the western notion that goal orientations are distinct from one another. Asian cultures exhibit a greater socially based collectivistic orientation (Berry et al., 2011), impacting on academic motivational orientation. Mastery goal orientation is aligned with more individualistically oriented cultures while performance goal orientation is associated with collectivist societies.

Cultural influences on learning approaches have received attention (Dennehy, 2015; Holtbrügge \& Mohr 2010; Signorini, Wiesemes, \& Murphy, 2009). Dennehy (2015) compared the learning approaches between Confucian-heritage and Western-heritage 
students, based on the stereotype that Asian students are more likely to adopt a 'surface learning approach' whereas Western students tend to adopt a 'deep learning approach' based on intrinsic/mastery motivation wherein students try to master the learning material, whereas surface learning reproduces facts through rote learning, rather than understanding underlying principles (Biggs, 2014; Biggs, Kember, \& Leung, 2001; Jongsataponsit, 2000; Phan, 2006). Approach-avoidance motivation plays a crucial role in students' cognitive and volitional regulatory abilities (Bartels, Magun-Jackson, \& Kemp, 2009).

Academic volitional strategies based on self-regulation theory, have been defined as "the degree to which individuals are metacognitively, motivationally, and behaviorally active participants in their own learning process" (Zimmerman, 1989). Self-regulation involves setting, monitoring, and managing learning behaviours and volitional strategies (emotional, motivational, cognitive and meta-cognitive control), in attaining academic goals (McCann \& Turner, 2004; Zimmerman, 2002; Zumbrunn, Tadlock, \& Roberts, 2011). Stress-reducing actions, self-efficacy enhancement, and negative-based incentives help students stay on task, enhancing academic performance (Bembenutty \& Karabenick, 2013; Shepherd, 2006). Selfefficacy enhancement helps maintain confidence, while negative-based incentives focus on undesirable consequences of poor academic performance (McCann \& Garcia, 1999). While self-regulatory learning studies have failed to examine culturally influenced individual differences (Lopez, 2000; McCann \& Garcia, 2000), nevertheless, Pintrich (1999) argued that cross-cultural assessment of self-regulatory and volitional strategies pertaining to academic learning is essential.

Subjective wellbeing (happiness) is associated with personal growth across the lifespan, positive emotions and mental health, pursuing one's intrinsic goals, self-acceptance, positive relationships, autonomy, environmental mastery, and purpose in life (Nielsen, 
Paritski, \& Smyth, 2009; Ryff et al., 2006). Both hedonism and eudaimonia (Huta, 2012) operate synergistically in contributing to happiness/psychological wellbeing (Henderson \& Knight, 2012; Kashdan, Biswas-Diener, \& King, 2008). According to Deci and Ryan (2008), in the hedonistic tradition, "the focus is on happiness, generally defined as the presence of positive affect and the absence of negative affect... [whereas] in the...eudaimonic tradition, the focus is on living life in a full and deeply satisfying way." Measures of happiness correlate positively with creative thinking, reading, leadership, confidence, self-esteem, selfefficacy, communication skills, and positive goal orientation (Dagenais-Demarais \& Sovoie, 2011; Fava \& Ruini, 2014), and with academic success (Datu, Valdez, \& King, 2017; Diener \& Seligman, 2002). Inarguably, culture defines the interpretation of happiness (e.g., Lou, Gilmour, \& Kao, 2001; Oishi, Graham, Kesebir, \& Galinha, 2013; Uchida \& Kitayama, 2009).

In contrast to the Judeo-Christian roots of Australian society, 93.6\% of Thai are Buddhist. To-date, individual differences in Thai vs. Australian academic performance have not been investigated as a function of motivational and cultural variables (cf. Hwang \& Matsumoto, 2013; Joy \& Kolb, 2009; King \& Watkins, 2013; McInerney \& Walker, 2011; Pimparyon, Roff, McAleer, Poonchai, \& Pemba, 2000). Wongsri (2004) had demonstrated that variables including happiness/psychological wellbeing (Schimmack, Radhakrishnan, Oishi, \& Dzokoto, 2002), goal orientation (Caraway, Tucker, Reinke, \& Hall, 2003), study approach (Biggs, 2014), and volitional strategies (McCann \& Turner, 2004) influence academic performance. In our study there are discernable cultural differences, as Thailand places more emphasis on conformity (e.g., university students required to wear uniforms), whereas in Australian universities, students are regarded as adults. The age of majority in Australia is 18 years, whereas in Thailand it is 21 years. In Thai universities, students are 
expected to listen carefully and respectfully without directly challenging the lecturer's authority or criticising his/her arguments. They may be required to memorise material, whereas Australian university students may be expected to adopt a more critical analytic style, and to more closely evaluate the statements and assertions of their lecturers.

\section{Aim of Present Study}

The present study investigated predictors of academic achievement among Thai and Australian university students. Standardised GPAs, measures of goal orientation, study approach, academic volitional strategies, and happiness/subjective wellbeing were obtained. Using a cross-cultural design, our study extends the work of Wongsri (2004) into the impact of learning-related predictors on academic performance and happiness/subjective wellbeing. Based on the literature review, we expected that Thai and Australian undergraduates would exhibit significant differences on several dependent measures.

\section{Method}

\section{Participants}

Students were enrolled in 4-year degree programs in Thailand and Australia. The combined sample $(\mathrm{N}=708)$, comprised $\mathrm{N}=395$ undergraduates at Saint Louis College, Bangkok, and N=313 undergraduates at XXXX XXXXXXXXXX, Queensland. Ethical clearance was granted both by the National Health and Medical Research Council (NHMRC) approved XXXX XXXXXXXXXX Human Research Ethics Committee (HREC), and by the corresponding XXXXX XXXXX XXXXXXXX Medical Research Ethics Committee (MREC). Only Asian students were included in the Thai sample, and only Caucasian students were included in the Australian sample. Students were asked to sign an informed consent form. Demographic characteristics are shown in Table 1. 
Table 1

\section{Design and Procedure}

A between-groups design with multiple dependent measures was employed. The independent variable (IV) was: Country (Thai vs. Australian). As discussed below, the measures included the Oxford Happiness Questionnaire (OHQ), the Goal Orientation Questionnaire (GOQ), the Revised Study Process Questionnaire (R-SPQ-2F), and the Academic Volitional Strategy Inventory (AVSI). Also, a preliminary demographics' sheet was completed by both the Thai and Australian students.

Standard translation procedures were followed. The cross-cultural translation technique advocated by Banville, Desrosiers, and Genet-Volet (2000) was employed with initial translation of the measures into Thai language carried out by two bilingual translators. Translating the items from English into Thai, with subsequent independent back-translation from Thai into English ensured that both language versions were equivalent (cf. Cantwell, Archer, \& Wongsri, 2002; Fetvadjiev \& van de Vijver, 2015; Hambleton, 2001; Hambleton, Swaminathan, \& Rogers, 1991; International Test Commission (ITC), 2005; Maneesriwongul \& Dixon, 2004; van de Vijver \& Hambleton, 1996; van de Vijver \& van Hemert, 2008; van de Vijver \& Tanzer, 2004; van de Vijver \& Poortinga, 2005). Content validity was assessed using a bilingual group of Thai students who completed both the English and Thai translated versions of the measurement scales. Testing the equivalence of the measures across the two cultural groups verified both their scalar and metric measurement invariance.

Establishing the cross-cultural equivalence of the Thai language and English language measures was absolutely imperative in order to enable valid between-group comparisons and 
to justify combining the two separate data sets in order to test the heuristic structural equation model (see below) of the empirically-observed interrelationships between the learning-related variables, happiness, and academic achievement.

Likewise, in order to enable direct comparison of academic achievement levels across the two samples, cumulative GPA scores (standardised on a 4-point scale for cross-country equivalence) were obtained from student records at both tertiary institutions, pursuant to informed consent having been obtained from the participants in each sample. XXXXX XXXXX XXXXXXX and XXXX XXXXXXXXXX are both private higher educational institutions.

\section{Measures}

Oxford Happiness Questionnaire (OHQ) - (Hills \& Argyle, 2002; Kashdan, 2004), includes 29 self-report items (17 direct; 12 reversed) measured on a 6-point scale ranging from "Strongly disagree" to "Strongly agree". Cronbach alpha coefficients (cf. Boyle, 1991) for the Thai measures (Australian data in parentheses) were: Total Scale: $\alpha=0.85(0.91)$, Direct items: $\alpha=0.89$ (0.91), and Reversed items: $\alpha=0.77$ (0.82). As for convergent validity, Hills and Argyle had reported correlations with measures of Extraversion ( $\mathrm{r}=0.61)$, Life Satisfaction $(r=0.77)$, Self-Esteem $(r=0.81)$, Life Orientation Test $(r=0.79)$, and Life Regard Index $(r=0.77)$. As for divergent validity, the OHQ correlated negatively with measures of Neuroticism $(r=-0.59)$, Psychoticism $(r=-0.17)$, and Depression $(r=-0.90)$.

Goal Orientation Questionnaire (GOQ) - (Adesope, Zhou, \& Nesbit, 2015; Midgley et al., 1998) comprises 18 self-report items rated on a 5-point scale ranging from "Almost Never or Never True" to "Almost Always or Always True". Alpha coefficients for the Thailanguage measures (Australian data in parentheses) were: Total Scale: $\alpha=0.82(0.82)$, Ability Approach Goal Orientation: $\alpha=0.81$ (0.79), Ability Avoid Goal Orientation: $\alpha=0.74$ 
(0.87), and Task Goal Orientation: $\alpha=0.73$ (0.82). Midgley et al. (1998) reported six-month retest coefficients for Task Goal Orientation $(\mathrm{r}=0.63)$, and Ability-Approach Goal Orientation $(r=0.61)$, indicating moderate stability. Ability-Approach and Ability-Avoid factors exhibited some measurement overlap (Thai sample: $r=0.55$; Australian sample: $r=$ $0.50)$.

Revised Study Process Questionnaire (R-SPQ-2F) - (Biggs, 2014; Biggs, Kember, \& Leung, 2001; Martinelli \& Raykov, 2017), comprises 20 self-report items rated on a 5-point scale ranging from "This item is never or only rarely true of me" to "This item is always or almost always true of me". Alpha coefficients (Australian data in parentheses) were: Total Scale: $\alpha=0.77$ (0.67), Deep Study Approach: $\alpha=0.79$ (0.82), and Surface Study Approach: $\alpha$ $=0.78(0.69)$.

Academic Volitional Strategy Inventory (AVSI) - (McCann \& Garcia, 1999; McCann \& Turner, 2004; Shepherd, 2006) comprises 30 self-report items rated on a 5-point scale ranging from "I almost never do this" to "I almost always do this". Alpha coefficients (Australian data in parentheses) were: Total Scale: $\alpha=0.87$ (0.89), Self-Efficacy Enhancement: $\alpha=0.80$ (0.85), Stress Reducing Actions: $\alpha=0.71(0.75)$, and Negative-Based Incentives: $\alpha=0.58(0.74)$ ), respectively. McCann and Garcia (1999) reported a stability coefficient over a 4-week interval $(r=0.72)$.

\section{Results}

Intercorrelations between background variables (country, sex, year, age) and also between learning-related variables (goal orientation, study process/approach), personality (happiness/psychological wellbeing) and GPA scores are shown in Table 2. It is evident that Country (Thailand vs. Australia) correlated substantially $(-.47, \mathrm{p}<.01)$ with academic grades 
measured via GPAs (22\% variance overlap) suggesting a discernible impact of culture on academic performance.

Table 2

Using SPSS (V21 for Windows), between-group MANCOVAs were carried out (with age, sex, and year level includes as covariates to control for between-group differences due to these background variables). The IV was Country (Thailand vs. Australia), while DVs were OHQ, GOQ, R-SPQ-2F and AVSI mean scores across groups (see Table 3), and the impact of AVSI subscale/domain scores on GPAs (see Table 4 below).

Table 3

\section{Happiness/Psychological Wellbeing}

Irrespective of Country (IV), there was a significant multivariate effect for Happiness/Psychological Wellbeing, $F(4,1362)=3.70, p<.001, \eta^{2}=.01$. Students with higher positive affectivity obtained significantly higher GPAs, $F(2,681)=6.89, p=.001, \eta^{2}$ $=.02$. However, our results accord with large-scale cross-cultural surveys based on the Programme for International Student Assessment (PISA) data showing that subjective Wellbeing reports among Thai students is significantly higher $(p<.05)$ than is the case for Western students (Lee \& Wu, 2019).

\section{Goal Orientation}


There was a significant multivariate effect of Country, $F(3,679)=31.89, p<.001$, $\eta^{2}=.12$, on Goal Orientation. Australian students scored more highly on Ability-Approach Orientation, $F(1,681)=82.53, p<.001, \eta^{2}=.11$. There was a significant univariate effect with Australian students obtaining significantly higher Ability-Avoid Orientation scores, $F(1$, $681)=3.83, p<.05$. Irrespective of Country, students with higher Ability-Approach Orientation scores obtained significantly lower GPAs, $F(2,681)=4.42, p<.01, \eta^{2}=.01$.

\section{Study Approach}

There was a significant multivariate effect of Country on Study Approach, $F(2,680)$ $\left.=10.99, p<.001, \eta^{2}=.03\right)$. There were significant univariate effects of Country on Deep Learning, $F(1,681)=14.84, p<.001, \eta^{2}=.02$, and on Surface Learning, $F(1,681)=6.54, p$ $=.011, \eta^{2}=.01$. Higher Deep Learning scores were obtained by Thai students (Table 4).

There was a significant multivariate effect for Year Level on Study Approach, $F(6$, $1360)=2.99, p<.01, \eta^{2}=.01$, plus a significant univariate effect, $F(3,681)=4.99, p$ $=.002$ ). A linear trend analysis (Fig. 1) suggests a monotonic decline in Deep Study Approach scores with increasing years of study, $F(3,681)=2.80, p<.04, \eta^{2}=.01$. There was a significant multivariate interaction between Country x Year Level, $F(6,1360)=3.38, p$ $=.003, \eta^{2}=.02$, and significant univariate interactions between Country $\mathrm{x}$ Year Level for both Deep and Surface Learning approaches, $F(3,681)=3.87, p<.01, \eta^{2}=.02 ; F(3,681)=$ $3.05, p=.03, \eta^{2}=.01$.

Figures $1 \& 2$ 


\section{Academic Volitional Strategies}

There was a significant multivariate effect of Country on AVSI scores, $F(3,679)=$ $58.65, p<.001, \eta^{2}=.20$ (Table 3 ), and a significant univariate effect of Country on StressReducing Actions (Australian students obtained lower scores), $F(1,681)=117.97, p<.001$, $\eta^{2}=.89$. Thai students obtained significantly higher Self-Efficacy Enhancement, $F(1,681)=$ 7.76, $p<.005, \eta^{2}=.01$, and Negative-Based Incentives scores, $F(1,681)=36.73, p<.001$, $\eta^{2}=.05$. There was a significant multivariate effect of AVSI scores on GPAs, $F(6,1358)=$ $4.40, p<.001, \eta^{2}=.02$. Students with higher Stress-Reducing Actions scores, higher SelfEfficacy Enhancement scores, and lower Negative-Based Incentives scores significantly obtained higher GPAs.

Table 4

The classification of GPA scores into Low, Medium, and High respectively, revealed overall that students with high levels of academic volitional motivation (Stress-Reducing Actions, Self-Efficacy Enhancement, and Negative-Based Incentives) obtained higher GPAs than did students with low AVSI subscale scores.

\section{Academic Performance Grades}

Irrespective of Country there was a significant multivariate effect of Study Approach on GPAs, $F(4,1360)=4.50, p<.001, \eta^{2}=.01$, and a monotonic increase in Deep Learning scores with increasing GPAs (Tukey's HSD, $\alpha=.05$ ). 


\section{Heuristic Structural Equation Model}

The univariate and multivariate statistical analyses clearly showed a significant impact of COUNTRY on academic performance (measured in terms of GPAs). However, as linear model effects are direct effects, one may wonder whether there are also any indirect effects of Country on GPA mediated by constructs underlying the learning-related and personality measures (before undertaking the SEM analysis, it was first verified that both the dependent variable and the model errors were normally distributed, with constant variance, and zero average, respectively).

Using the combined sample data $(\mathrm{N}=708)$ and EQS (Version 6.3; Bentler, 2015; Ullman \& Bentler, 2013), a heuristic structural equation model (SEM) was constructed to predict GPA and Happiness/Psychological Wellbeing from the demographic and self-report measures with two distinct latent factors (F1, Goal Orientation; F2, Academic Volitional Strategies). After trimming non-significant parameters and adding residual correlations, the model in Figure 3 provided a satisfactory fit to the empirical data (robust chi-square, $\chi^{2}$ $(61 \mathrm{df})=203.80$, robust $C F I=.95$, robust $R M S E A=.06, R M S R=.05$ (cf. Byrne, 2006; Hu \& Bentler, 1995; Kline, 2010; Yuan \& Bentler, 2007; Yuan, Chan, Marcoulides, \& Bentler 2016).

Figure 3

As Figure 3 shows, GPA was predicted by F1 (Goal Orientation) as well as four observed variables. Beta coefficients for F1, GOQ_TASK, SPQ_SLA, and SEX were about .10 while the beta coefficient for COUNTRY was -.50 , with overall $\mathrm{R}^{2}=.26$. COUNTRY indirectly impacted on GPA via F1 $(\mathrm{p}<.001)$. The SEM model also shows that 
Happiness/Psychological wellbeing was predicted by F2 (Academic Volitional Strategies) (.30), and by GOQ_TASK (.20), with an overall multiple $\mathrm{R}^{2}=.20$. The SEM confirms that the major predictor of GPAs was COUNTRY, highlighting the significant $(\mathrm{p}<.001)$ impact of cultural influence on academic performance (GPAs) among university undergraduate students. As shown in Figure 3, both Approach-Goal Orientation and Avoidance Goal Orientation factors impacted significantly $(\mathrm{p}<.001)$ on GPA scores.

\section{Discussion}

Personality (Happiness/Psychological wellbeing) was positively associated with higher GPA scores, suggesting that irrespective of culture, happier students exhibit superior academic performance. Ability-approach and ability-avoidance scores were higher among Australian students. Although there is evidence that Western students may exhibit higher mastery (task-orientation) and performance-approach goal orientation than Asian students (Dekker \& Fischer, 2008), Thai students obtained higher deep study approach scores, consistent with the higher proportion of third- and fourth-year undergraduates $(49.3 \%)$ as compared with only $18 \%$ of third- and fourth-year Australian undergraduates. Our findings concur with Marambe, Vermunt, and Boshuizen (2012) that, "Asian learners would have a propensity for rote learning turned out to be a myth... Some patterns of learning turned out to be universal..."

Thai students obtained higher scores on AVSI strategies (self-efficacy enhancement, stress reducing actions, and negative-based incentives). Those with higher GPAs reported greater self-efficacy enhancement than Australian students. Irrespective of culture, those with higher stress-reducing actions and self-efficacy enhancement scores, and lower negativebased incentives scores obtained higher GPAs. 
Although the Australian students obtained lower mean GPAs, $82 \%$ of the Australian sample were either first- or second-year undergraduates (vs. $50.7 \%$ of the Thai sample). In general, higher scores on psychological wellbeing (OHQ), task goal orientation (GOQ), deep study approach (R-SPQ-2F), stress-reducing actions, self-efficacy enhancement, and lower negative-based incentives (AVSI) were directly related to higher GPAs.

The present findings confirm that personality and learning-related variables impact significantly on academic achievement among samples of Thai and Australian undergraduate students. Multiple significant differences in motivation and learning styles were found between the Australian and Thai students, showing that cultural factors play a role in influencing academic learning outcomes (as measured by cumulative GPAs in both samples). The heuristic SEM model provided further support for the notion that culture impacted significantly on academic performance outcomes.

\section{Conclusions and Limitations}

While cultural factors may account for some $20 \%$ of the variance in differential academic performance outcomes, one caveat is that the traditional concept of culture is hampered by the ever-increasing present-day cultural diversity (Abdallah-Pretceille, 2006), particularly with the advent of the ever-increasing plethora of social media platforms. The multicultural nature of both modern Australia and modern Thailand defies simple categorisation as "Western" or "Asian" respectively. University undergraduate students (especially in multicultural societies such as Australia) now typically come from a wide range of cultural backgrounds. Hong and Mallorie (2004) have pointed to the dynamic nature of culture in the modern world. Thus, ongoing technological advancements as well as globalisation have resulted in ever-increasing levels of cultural diversity, making simple “cross-cultural" comparisons increasingly problematic. This increase in cultural diversity 
may be reducing the impact of culturally specific personality and learning styles on academic performance outcomes. In addition, it is possible that differences in personality, motivation, and learning-related variables reported by students across the two countries also may be impacted by the large difference in GDP per capita, impacting on the quality of education across the two countries which may in turn impact on students' academic performance.

Moreover, as the two samples differed in the proportion of students from each of the four undergraduate year levels, and also differed modestly on participant sex, the present findings need to be interpreted with care. As well, the cross-sectional nature of the present study necessarily precludes causal interpretations. The study was also based on the perspectives of students. The results might have differed somewhat from our present findings if the study had relied on the instructors' responses. As well, there may been some heterogeneity in the associations between the personality, learning-related, and academic performance variables depending on the differences in specific coursework completed by the Thai and Australian participants, respectively. As compared with the study of psychology, some natural science or technical programs of study may have fewer opportunities for broader knowledge testing. Furthermore, as measures were obtained across four separate years of the respective degree programs, the likelihood that deep study approaches might be employed more in later years of education was potentially problematic. Such limitations should be controlled in future research studies in this area. Further research is highly recommended, including a replication of this personality-learning study, as well as similar cross-cultural comparisons across a variety of different Asian and Western societies. 


\section{References}

Abdallah-Pretceille, M. (2006). Interculturalism as a paradigm for thinking about diversity. Intercultural Education, 17, 475-483.

Adesope, O. O., Zhou, M., \& Nesbit, J. C. (2015). Achievement goal orientations and selfreported study strategies as predictors of online studying activities. Journal of Educational Computing Research, 53, 436-458.

Banville, D., Desrosiers, P., \& Genet-Volet, Y. (2000). Translating questionnaires and inventories using a cross-cultural translation technique. Journal of Teaching in Physical Education, 19, 374-387.

Bartels, J. M., Magun-Jackson, S., \& Kemp, A. D. (2009). Volitional regulation and selfregulated learning: An examination of individual differences in approach-avoidance achievement motivation. Electronic Journal of Research in Educational Psychology, 7, 605-626.

Bembenutty, H., \& Karabenick, S. A. (2013). Self-Regulation, culture, and academic delay of gratification. Journal of Cognitive Education and Psychology 12, 323-337.

Bernardo, A. B. I. (2003). Do Filipino youth really value education? Exploring Filipino adolescents' beliefs about the abstract and pragmatic value of education and its relationship to achievement goals and learning strategies. Philippine Journal of Psychology, 36, 49-67.

Bernardo, A. B., \& Liem, G. A. D. (2013). Mapping the spaces of cross-cultural educational psychology. In G.A.D. Liem, \& A. B. I. Bernardo (Eds.), Advancing cross-cultural perspectives on educational psychology. (pp. 345-357). Greenwich, CT: IAP.

Berry, J. W., Poortinga, Y. H., Breugelmans, S. M., Chasiotis, A., \& Sam, D. L. (2011). Cross-cultural psychology: Research and applications ( ${ }^{\text {rd }}$ ed.). Cambridge: CUP.

Biggs, J. B. (2014). Students' approaches to learning. URL:

http://www.johnbiggs.com.au/academic/students-approaches-to-learning/ (Retrieved April 23, 2017).

Biggs, J. B., Kember, D., \& Leung, D. Y. P. (2001). The revised two-factor Study Process Questionnaire: R-SPQ-2F. British Journal of Educational Psychology, 71, 133-149.

Boyle, G. J. (1991). Does item homogeneity indicate internal consistency or item redundancy in psychometric scales? Personality and Individual Differences, 12, 291-294. 
Boyle, G. J., Saklofske, D. H., Matthews, G. (2015). Criteria for selection and evaluation of scales/measures. In G. J. Boyle et al. (Eds.), Measures of personality and social psychological constructs (pp. 3-15). San Diego, CA: Elsevier/Academic.

Brdar I., Rijavec M., \& Miljković D. (2009). Life goals and wellbeing: Are extrinsic aspirations always detrimental to wellbeing? Psychological Topics, 18, 317-334.

Byrne, B. M. (2006). Structural equation modeling with EQS: Basic concepts, applications, and programming (2nd ed.). Mahwah, NJ: Erlbaum.

Cantwell, R. H., Archer, J., \& Wongsri, N. (December 2002). The validation of measures of self-efficacy, motivation and self-regulated learning among Thai tertiary students. Paper presented at the Annual AARE Conference, Brisbane.

Caraway, K., Tucker, C. M., Reinke, W. W., \& Hall, C. (2003). Self-efficacy, goal orientation, and fear of failure as predictors of school engagement in high school students. Psychology in the Schools, 40, 417-427.

Chang, L., Mak, M. C. K., Li, T., Wu, B. P., Chen, B. B., \& Lu, H. J. (2011). Cultural adaptations to environmental variability: An evolutionary account of East-West differences. Educational Psychology Review, 23, 99-129.

Chang, W.C., \& Wong, W. K. (2008). Individual-oriented and social-social oriented achievement motivation of Singaporean Chinese. Journal of Psychology in Chinese Societies, 1, 39-63.

Chiu, C-Y, Kim, Y-H, \& Wan, W. W. N. (2008). Personality: Cross-cultural perspectives. In G. J. Boyle et al. (Eds.), The SAGE handbook of personality theory and assessment: Vol. 1 - Personality theories and models (pp. 124-144). Los Angeles, CA: Sage.

Chiu, C-Y, Chia, S. I., \& Wan, W. W. N. (2015). Measures of cross-cultural values, personality and beliefs. In G. J. Boyle et al. (Eds.), Measures of personality and social psychological constructs (pp. 621-651). San Diego, CA: Elsevier/Academic.

Choi, K., \& Kim, D. (2013). A cross-cultural study of antecedents on career preparation behavior: Learning motivation, academic achievement, and career decision selfefficacy. Journal of Hospitality, Leisure, Sport \& Tourism Education, 13, 19-32.

Datu, J. A. D., Valdez, J. P. M., \& King, R. B. (2017). Exploring the association between peace of mind and academic engagement: Cross-sectional and cross-lagged panel studies in the Philippine context. Journal of Happiness Studies. 
Dagenais-Desmarais, V., \& Savoie, A. (2012). What is psychological well-being really? A grassroots approach from the organizational sciences. Journal of Happiness Studies, 13, 659-684.

Deci, E. L., \& Ryan, R. M. (2008). Hedonia, eudaimonia, and wellbeing: An introduction. Journal of Happiness Studies, 9, 1-11.

Dekker, S., \& Fischer, R. (2008). Cultural differences in academic motivation goals: A metaanalysis across 13 societies. Journal of Educational Research, 102, 99-110.

Dela Rosa, E. D., \& Bernardo, A. B. I. (2013). Testing multiple goals theory in an Asian context: Filipino university students' motivation and academic achievement. International Journal of School and Educational Psychology, 1, 45-57.

Dennehy, E. (2015). Learning approaches and cultural influences: A comparative study of Confucian and Western-heritage students, Journal of Further and Higher Education, 39, 818-838.

Diener, E., \& Seligman, M. E. P. (2002). Very happy people. Psychological Science, 13, 8184.

Elliot, A. J., \& Murayama, K. (2008). On the measurement of achievement goals: Critique, illustration, and application. Journal of Educational Psychology, 100, 613-628.

Fava, G. A., \& Ruini, C. (2014). (Eds.), Increasing psychological wellbeing in clinical and educational settings: Interventions and cultural contexts. Dordrecht, The Netherlands: Springer.

Fernández, R., (August 2010). Does culture matter? NBER Working Paper No. w16277. Available at SSRN: https://ssrn.com/abstract $=1662271$

Fetvadjiev, V. H., \& van de Vijver, F. J. R. (2015). Measures of personality across cultures. In G. J. Boyle, D. H. Saklofske, \& G. Matthews (Eds.), Measures of personality and social psychological constructs (pp. 752-776). San Diego, CA: Elsevier/Academic Press.

Gao, Z., Xiang, P., Harrison, L., Guan, J., \& Rao, Y. (2008). A cross-cultural analysis of achievement goals and self-efficacy between American and Chinese college students in physical education. International Journal of Sport Psychology, 39, 312-328.

Gong, Y., \& Fan, J. (2006). Longitudinal examination of the role of goal orientation in crosscultural adjustment. Journal of Applied Psychology, 91, 176-184. 
Hambleton, R. K. (2001). The next generation of the ITC test translation and adaptation guidelines. European Journal of Psychological Assessment, 17, 164-172.

Hambleton, R. K., Swaminathan, H., \& Rogers, H. J. (1991). Fundamentals of item response theory. Newbury Park, CA: Sage.

Heffernan, T., Morrison, M., Basu, P., \& Sweeney, A. (2010). Cultural differences, learning styles and transnational education. Journal of Higher Education Policy and Management, 32, 27-39.

Henderson, L. W., \& Knight, T. (2012). Integrating the hedonic and eudaimonic perspectives to more comprehensively understand wellbeing and pathways to wellbeing. International Journal of Wellbeing, 2, 196-221.

Hills, P., \& Argyle, M. (2002). The Oxford Happiness Questionnaire: A compact scale for the measurement of psychological well-being. Personality and Individual Differences, 33, 1073-1082.

Ho, I. T., \& Hau, K-T. (2008). Academic achievement in the Chinese context: The role of goals, strategies, and effort. International Journal of Psychology, 43, 892-897.

Holtbrügge, D., \& Mohr, A. (2010), Cultural determinants of learning style preferences. Academy of Management Learning \& Education, 9, 622-637.

Hong, Y-Y., \& Mallorie, L. M. (2004). A dynamic constructivist approach to culture: Lessons learned from personality psychology. Journal of Research in Personality, 38, 59-67.

Hsin, A., \& Xie, Y. (2014). Explaining Asian Americans' academic advantage over whites. Proceedings of the National Academy of Sciences of the United States of America, $111(23), 8416-8421$.

Hu, L. T., \& Bentler, P. M. (1995). Evaluating model fit. In R. Hoyle (Ed.), Structural equation modeling: Concepts, issues, and applications (pp.76-99). Thousand Oaks, CA: Sage.

Huta, V. (2012). Linking peoples' pursuit of eudaimonia and hedonia with characteristics of their parents: Parenting styles, verbally endorsed values, and role modeling. Journal of Happiness Studies, 13, 47-61. 
Hwang, H. C., \& Matsumoto, D. (2013). Culture and educational psychology. In G.A.D. Liem, \& A. B. I. Bernardo (Eds.), Advancing cross-cultural perspectives on educational psychology (pp. 21-37). Greenwich, CT: IAP.

ITC Guidelines for Translating and Adapting Tests (2005). International Test Commission. Document reference: ITC-G-TA-20140617 URL: https://www.intestcom.org/files/guideline test adaptation.pdf (Retrieved 15 Feb 2018) Jongsataponsit, S. (2000). A study of learning approaches in an English language subject. Masters Thesis, Chulalongkorn University, Bangkok, Thailand.

Joy, S., \& Kolb, D. A. (2009). Are there cultural differences in learning style? International Journal of Intercultural Relations, 33, 69-85.

Kang, H., \& Chang, B., (2016). Examining culture's impact on the learning behaviors of international students from Confucian culture studying in Western online learning context. Journal of International Students, 6, 779-797.

Kashdan, T. B. (2004). The assessment of subjective well-being (issues raised by the Oxford Happiness Questionnaire). Personality and Individual Differences, 36, 1225-1232.

Kashdan, T. B., Biswas-Diener, R., \& King, L. A. (2008). Reconsidering happiness: The costs of distinguishing between hedonics and eudaimonia. Journal of Positive Psychology, 3, 219-233.

King, R. B., \& Watkins, D. A. (2013). Cultivating a "cultural imagination" in school motivation research: Recommendations for moving forward. In G.A.D. Liem, \& A. B. I. Bernardo (Eds.), Advancing cross-cultural perspectives on educational psychology (pp. 59-86). Greenwich, CT: IAP.

Klassen,R., Wilson, E., Siu, A.F. Y., Hannok, W., Wong, M. W., Wongsri, N., Sonthisap, P., Pibulchol, C., Buranachaitavee, Y., \& Jansem, A. (2013). Preservice teachers' work stress, self-efficacy, and occupational commitment in four countries. European Journal of Psychology of Education, 28, 4, 1289.

Kline, R. B. (2010). Principles and practice of structural equation modeling (3rd ed.). New York: Guilford.

Lau, K-L., \& Lee, J. (2008). Examining Hong Kong students' achievement goals and their relations with students' perceived classroom environment and strategy use. Educational Psychology, 28, 357-372. 
Lee, J., \& Wu, Y-J. (2019). Student well-being around the world: Cross-national examination based on PISA 2015 data. Paper presented at the Australian Conference on Personality and Individual Differences (ACPID), QUT, Gardens Point, Brisbane, 29 November.

Lopez, D. F. (2000). Social cognitive influences on self-regulated learning: The impact of action control beliefs and academic goals on achievement-related outcomes. Learning and Individual Differences, 11, 301-319.

Lou, L., Gilmour, R., \& Kao, S-F (2001). Cultural values and happiness: An East-West dialogue. Journal of Social Psychology, 141, 477-493.

Macayan, J. V. (2012). Asians' conception of achievement goals: An analytic review. SLHS Review, 1, 1-11.

Manikutty, S., Anuradha, N.S. \& Hansen,K. (2007). Does culture influence learning styles in higher education? International Journal of Learning and Change, 2, 70-87.

Maneesriwongul, W., \& Dixon, J. K. (2004). Instrument translation process: A methods review. Journal of Advanced Nursing, 48, 175-186.

Marambe, K. N., Vermunt, J. D., \& Boshuizen, H. P. A. (2012). A cross-cultural comparison of student learning patterns in higher education. Higher Education 64, 299-316.

Martinelli, V., \& Raykov, M. (2017). Evaluation of the Revised Two-Factor Study Process Questionnaire (R-SPQ-2F) for student teacher approaches to learning. Journal of Educational and Social Research, 7, 9-13.

McCann, E. J., \& Garcia, T. (1999). Maintaining motivation and regulating emotion: Measuring individual differences in academic volitional strategies. Learning and Individual Differences, 11, 259-279.

McCann, E. J., \& Turner, J. E. (2004). Increasing student learning through volitional control. Teachers College Record, 106, 1695-1714.

McInerney, D. M., \& Walker, R. A. (2011). (Eds.), Sociocultural theories of learning and motivation: Looking back, looking forward. Greenwich, CT: IAT.

Midgley, C., Kaplan, A., Middleton, M., ... \& Roeser, R. (1998). The development and validation of scales assessing students' achievement goal orientations. Contemporary Educational Psychology, 23, 113-131.

Nielsen, I., Paritski, O., \& Smyth, R. (2009). Subjective well-being of Beijing taxi drivers, Journal of Happiness Studies, 11, 721-733. 
Oishi, S., Graham, J., Kesebir, S., \& Galinha, I. C. (2013). Concepts of happiness across time and cultures. Personality and Social Psychology Bulletin, 39, 559-577.

Phan, H.P. (2006). Examination of student learning approaches, reflective thinking, and epistemological beliefs: A latent variables approach. Journal of Research in Educational Psychology, 10, 577-610.

Pimparyon, P., Roff, S., McAleer, S., Poonchai, B., \& Pemba, S. (2000). Educational environment, student approaches to learning and academic achievement in a Thai nursing school. Medical Teacher, 22, 359-364.

Pintrich, P. R. (1999). The role of motivation in promoting and sustaining self-regulated learning. International Journal of Educational Research, 31, 459-470.

Ryff, C.D., Love, G. D., Urry, H. L., Muller, D., Rosenkranz, M. A., Friedman, E. M., Davidson, R. J., Singer, B. (2006). Psychological wellbeing and ill-being: Do they have distinct or mirrored biological correlates? Psychotherapy and Psychosomatics, $75,85-95$.

Saklofske, D. H., \& Eysenck, H. J. (2004). Extraversion-Introversion. In G. J. Boyle, \& D. H. Saklofske (2004). (Eds.), The psychology of individual differences, Vol. 2: Personality (pp. 203-222). London: Sage.

Salili, F., Chiu, C., \& Lai, S. (2001). The influence of culture and context on students' motivational orientation and performance. In F. Salili et al. (Eds.), Student motivation: The culture and context of learning (pp. 221-247). New York: Kluwer/Plenum.

Schimmack, U., Radhakrishnan, P., Oishi, S., \& Dzokoto, V. (2002). Culture, personality, and subjective wellbeing: Integrating process models of life satisfaction. Journal of Personality and Social Psychology, 88, 582-593.

Signorini, P., Wiesemes, R., \& Murphy, R. (2009). Developing alternative frameworks for exploring intercultural learning: A critique of Hofstede's cultural difference model, Teaching in Higher Education, 14, 253-264.

Shepherd, R-M. (2006). Volitional strategies and social anxiety among college students. The College Quarterly, 9(4). Toronto, ON: Seneca College of Applied Arts and Technology. 
Stankov, L., \& Lee, J. (2008). Culture: Ways of thinking and believing. In G. J. Boyle et al. (Eds.), The SAGE handbook of personality theory and assessment: Vol. 1 Personality theories and models (pp. 560-575). Los Angeles, CA: Sage.

Uchida, Y., \& Kitayama, S. (2009). Happiness and unhappiness in East and West: Themes and variations. Emotion, 9, 441-456.

Ullman, J. B., \& Bentler, P. M. (2013). Structural equation modeling. In I. B. Weiner (Ed.), Handbook of Psychology (2 ${ }^{\text {nd }}$ ed.). (pp. 661-690). New York: Wiley.

van de Vijver, F. J. R., \& Hambleton, R. K. (1996). Translating tests: Some practical guidelines. European Psychologist, 1, 89-99.

van de Vijver, F. J. R., \& Poortinga, Y. H. (2005). Conceptual and methodological issues in adapting tests. In R. K. Hambleton, P. F. Merenda, \& C. D. Spielberger (Eds.), Adapting educational tests and psychological tests for cross-cultural assessment (pp. 39-64). Mahwah, NJ: Erlbaum.

van de Vijver, F. J. R., \& Tanzer, N. K. (2004). Bias and equivalence in cross-cultural assessment: An overview. European Review of Applied Psychology, 54, 119-135.

van de Vijver, F. J. R., \& van Hemert, D. A. (2008). Cross-cultural personality assessment. In G. J. Boyle, G. Matthews, \& D. H. Saklofske (Eds.), The SAGE handbook of personality theory and assessment: Vol. 2 - Personality measurement and testing (pp. 55-72). Los Angeles, CA: Sage.

Watson, A. M., Meade, A. W., Surface, E. A., \& van de Walle, D. (2007). Are goal orientation comparisons appropriate between American and Korean groups? Paper presented at the $22^{\text {nd }}$ SIOP Meeting, New York: SIOP.

Wongsri, N. (2004). A cross-cultural and cross disciplinary comparison of some components of self-regulated learning. Doctoral Dissertation, University of Newcastle, NSW.

Yeo, G., Loft, S., Xiao, T., \& Kiewitz, C. (2009). Goal orientations and performance: Differential relationships across levels of analysis and as a function of task demands. Journal of Applied Psychology, 94, 710-726.

Yu, A. B., \& Yang, K. S. (1994). The nature of achievement motivation in collectivist societies. In U. Kim, H. C. Triandis, C. Kagitcibasi, S. C. Choi, \& G. Yoon (Eds.), 
Individualism and collectivism: Theory, method, and applications (pp. 239-250).

Thousand Oaks, CA: Sage.

Yuan, K-H., \& Bentler, P. M. (2007). Robust procedures in structural equation modeling. In E.J. Kontoghiorghes (Ed.). Handbook of computing and statistics with applications, Vol. 1. (pp. 367-397). Amsterdam: The Netherlands: Elsevier.

Yuan, K.-H., Chan, W., Marcoulides, G. A., \& Bentler, P. M. (2016). Assessing structural equation models by equivalence testing with adjusted fit indexes. Structural Equation Modeling, 23, 319-330.

Zimmerman, B. J. (1989). A social cognitive view of self-regulated academic learning. Journal of Educational Psychology, 81, 329-339.

Zimmerman, B. J. (2002). Becoming a self-regulated learner: An overview. Theory into Practice, 41, 64-70.

Zumbrunn, S., Tadlock, J., \& Roberts, E. D. (2011). Encouraging self-regulated learning in the classroom: A review of the literature. Metropolitan Educational Research Consortium (MERC), Richmond VA: Virginia Commonwealth University. 
Table 1

Demographic characteristics of Australian and Thai University Students

\begin{tabular}{lrrrr}
\hline Demographic variables & \multicolumn{4}{c}{ Country } \\
\cline { 2 - 5 } & \multicolumn{3}{c}{ Australian $(N=313)$} & \multicolumn{2}{c}{ Thai $(N=395)$} \\
\cline { 2 - 5 } & \multicolumn{1}{c}{$N$} & $\%$ & $N$ & $\%$ \\
\hline Sex & 69 & 22.00 & 26 & 6.60 \\
$\quad$ Male & 244 & 78.00 & 369 & 93.40 \\
$\quad$ Female & & & & \\
Year of study & 92 & 29.40 & 82 & 20.80 \\
$\quad$ First year & 165 & 52.60 & 118 & 29.90 \\
Second year & 39 & 12.50 & 103 & 26.10 \\
$\quad$ Third year & 17 & 5.50 & 92 & 23.20 \\
Fourth year and others & & & & \\
GPA & 263 & 84.00 & 278 & 70.40 \\
$\quad$ Credit and below & 50 & 16.00 & 117 & 29.60 \\
$\quad$ Distinction or High Distinction & & &
\end{tabular}

Note. Total $N=708$. 
Table 2

Intercorrelation matrix for combined Australian and Thai data $(\mathbf{N}=708)$

\begin{tabular}{|c|c|c|c|c|c|c|c|c|}
\hline & $\stackrel{尺}{\stackrel{8}{8}}$ & $\underset{\mathscr{X}}{\mathscr{X}}$ & 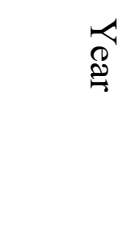 & $\underset{0}{D}$ & 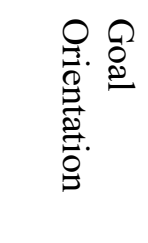 & 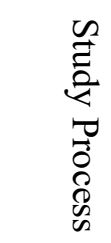 & 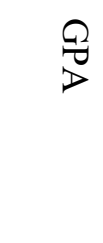 & 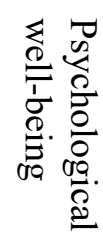 \\
\hline $\begin{array}{l}\text { Country } \\
\text { Sex } \\
\text { Year } \\
\text { Age } \\
\text { Goal Orientation } \\
\text { Study Process } \\
\text { GPA } \\
\text { Psychological Wellbeing }\end{array}$ & $\begin{array}{l}-.23 * * \\
-.28 * * \\
.26 * * \\
.28 * * \\
-.26 * * \\
-.47 * * \\
.03\end{array}$ & $\begin{array}{l}.11^{* *} \\
-.01 \\
-.05 \\
.02 \\
.19^{* *} \\
.02\end{array}$ & $\begin{array}{c}.09^{*} \\
-.11^{*} \\
.11^{*} \\
.13^{*} \\
-.04\end{array}$ & $\begin{array}{l}.04 \\
-.02 \\
-.09 * \\
.07\end{array}$ & $\begin{array}{l}.25 * * \\
-.08 * \\
-.06\end{array}$ & $\begin{array}{l}.10^{*} \\
-.03\end{array}$ & $.13^{*}$ & 1 \\
\hline
\end{tabular}


Table 3

Means, standard deviations and Cronbach alpha coefficients for the Thai and Australian personality and learning-related variables

\begin{tabular}{|c|c|c|c|c|c|c|}
\hline \multirow[t]{2}{*}{ Instrument } & \multirow[t]{2}{*}{ Domain } & \multirow[t]{2}{*}{$\begin{array}{l}\text { No. of } \\
\text { items }\end{array}$} & \multicolumn{3}{|c|}{$\begin{array}{l}\text { Mean } \\
\text { (SD) }\end{array}$} & \multirow[t]{2}{*}{$\begin{array}{c}\text { Alpha } \\
\text { coefficient }\end{array}$} \\
\hline & & & Overall & Thai & Australian & \\
\hline \multirow[t]{3}{*}{$\mathrm{OHQ}$} & Positive Affect & 17 & $\begin{array}{l}4.42 \\
(.76)\end{array}$ & $\begin{array}{l}4.44 \\
(.04)\end{array}$ & $\begin{array}{l}4.40 \\
(.04)\end{array}$ & 0.90 \\
\hline & Negative Affect & 12 & $\begin{array}{l}4.25 \\
(.79) \\
\end{array}$ & $\begin{array}{l}4.05 \\
(.04) \\
\end{array}$ & $\begin{array}{l}4.45 \\
(.04)\end{array}$ & 0.79 \\
\hline & $\begin{array}{l}\text { Task Goal } \\
\text { Orientation }\end{array}$ & 6 & $\begin{array}{l}3.22 \\
(.51)\end{array}$ & $\begin{array}{l}3.17 \\
(.47)\end{array}$ & $\begin{array}{l}3.27 \\
(.56)\end{array}$ & 0.78 \\
\hline \multirow[t]{2}{*}{ GOQ } & $\begin{array}{l}\text { Ability-Approach } \\
\text { Goal Orientation }\end{array}$ & 6 & $\begin{array}{l}3.05 \\
(.86)\end{array}$ & $\begin{array}{l}2.59 \\
(.78)\end{array}$ & $\begin{array}{l}3.51 \\
(.80)\end{array}$ & 0.83 \\
\hline & $\begin{array}{l}\text { Ability-Avoid Goal } \\
\text { Orientation }\end{array}$ & 6 & $\begin{array}{l}2.67 \\
(.84) \\
\end{array}$ & $\begin{array}{l}2.57 \\
(.78) \\
\end{array}$ & $\begin{array}{l}2.78 \\
(.90) \\
\end{array}$ & 0.82 \\
\hline \multirow[t]{3}{*}{$R-S P Q-2 F$} & Deep Learning & 10 & $\begin{array}{l}3.24 \\
(.66)\end{array}$ & $\begin{array}{l}3.40 \\
(.58)\end{array}$ & $\begin{array}{l}3.05 \\
(.70)\end{array}$ & 0.81 \\
\hline & Surface Learning & 9 & $\begin{array}{l}2.62 \\
(.64) \\
\end{array}$ & $\begin{array}{l}2.67 \\
(.64) \\
\end{array}$ & $\begin{array}{l}2.55 \\
(.64) \\
\end{array}$ & 0.77 \\
\hline & $\begin{array}{l}\text { Stress-Reducing } \\
\text { Actions }\end{array}$ & 10 & $\begin{array}{l}2.99 \\
(.73)\end{array}$ & $\begin{array}{l}3.34 \\
(.54)\end{array}$ & $\begin{array}{l}2.54 \\
(.69)\end{array}$ & 0.80 \\
\hline \multirow[t]{2}{*}{ AVSI } & $\begin{array}{l}\text { Self-Efficacy } \\
\text { Enhancement }\end{array}$ & 13 & $\begin{array}{l}3.68 \\
(.60)\end{array}$ & $\begin{array}{l}3.79 \\
(.52)\end{array}$ & $\begin{array}{l}3.55 \\
(.67)\end{array}$ & 0.83 \\
\hline & $\begin{array}{l}\text { Negative-Based } \\
\text { Incentives }\end{array}$ & 7 & $\begin{array}{l}3.61 \\
(.70) \\
\end{array}$ & $\begin{array}{l}3.81 \\
(.54) \\
\end{array}$ & $\begin{array}{l}3.35 \\
(.78) \\
\end{array}$ & 0.71 \\
\hline
\end{tabular}

Notes: $\mathrm{N}_{\text {Total }}=708 ; \mathrm{N}_{\text {Thai }}=395 ; \mathrm{N}_{\text {Aust. }}=313$. 
Table 4

Academic Volitional Strategies Inventory subscale scores by Country and GPA

\begin{tabular}{|c|c|c|c|c|}
\hline \multirow[t]{2}{*}{ AVSI domain } & \multirow[t]{2}{*}{$\begin{array}{l}\text { GPA } \\
\text { level }\end{array}$} & \multicolumn{3}{|c|}{$\begin{array}{c}\text { Mean } \\
\text { (SD) }\end{array}$} \\
\hline & & Overall & Thai & Australian \\
\hline \multirow{3}{*}{$\begin{array}{c}\text { Stress Reducing } \\
\text { Actions }\end{array}$} & Low & $\begin{array}{l}2.72 \\
(.75)\end{array}$ & $\begin{array}{l}3.23 \\
(.55)\end{array}$ & $\begin{array}{l}2.56 \\
(.74)\end{array}$ \\
\hline & Mod & $\begin{array}{l}3.12 \\
(.70)\end{array}$ & $\begin{array}{l}3.38 \\
(.54)\end{array}$ & $\begin{array}{l}2.31 \\
(.62)\end{array}$ \\
\hline & High & $\begin{array}{l}3.13 \\
(.67)\end{array}$ & $\begin{array}{l}3.31 \\
(.54)\end{array}$ & $\begin{array}{l}2.51 \\
(.59)\end{array}$ \\
\hline \multirow{3}{*}{$\begin{array}{l}\text { Self-Efficacy } \\
\text { Enhancement }\end{array}$} & Low & $\begin{array}{l}3.55 \\
(.68)\end{array}$ & $\begin{array}{l}3.52 \\
(.63)\end{array}$ & $\begin{array}{l}3.59 \\
(.70)\end{array}$ \\
\hline & Mod & $\begin{array}{l}3.69 \\
(.57)\end{array}$ & $\begin{array}{l}3.77 \\
(.51)\end{array}$ & $\begin{array}{l}3.29 \\
(.66)\end{array}$ \\
\hline & High & $\begin{array}{l}3.79 \\
(.51) \\
\end{array}$ & $\begin{array}{l}3.85 \\
(.46) \\
\end{array}$ & $\begin{array}{l}3.62 \\
(.59) \\
\end{array}$ \\
\hline \multirow{3}{*}{$\begin{array}{l}\text { Negative-Based } \\
\text { Incentives }\end{array}$} & Low & $\begin{array}{l}3.51 \\
(.74)\end{array}$ & $\begin{array}{l}3.67 \\
(.67)\end{array}$ & $\begin{array}{l}3.60 \\
(.75)\end{array}$ \\
\hline & Mod & $\begin{array}{l}3.67 \\
(.71)\end{array}$ & $\begin{array}{l}3.89 \\
(.52)\end{array}$ & $\begin{array}{l}3.06 \\
(.82)\end{array}$ \\
\hline & High & $\begin{array}{l}3.64 \\
(.64) \\
\end{array}$ & $\begin{array}{l}3.78 \\
(.51) \\
\end{array}$ & $\begin{array}{l}3.16 \\
(.76) \\
\end{array}$ \\
\hline
\end{tabular}

Notes: $\mathrm{N}_{\text {Total }}=708 ; \mathrm{N}_{\text {Thai }}=395 ; \mathrm{N}_{\text {Aust }}=313$. 


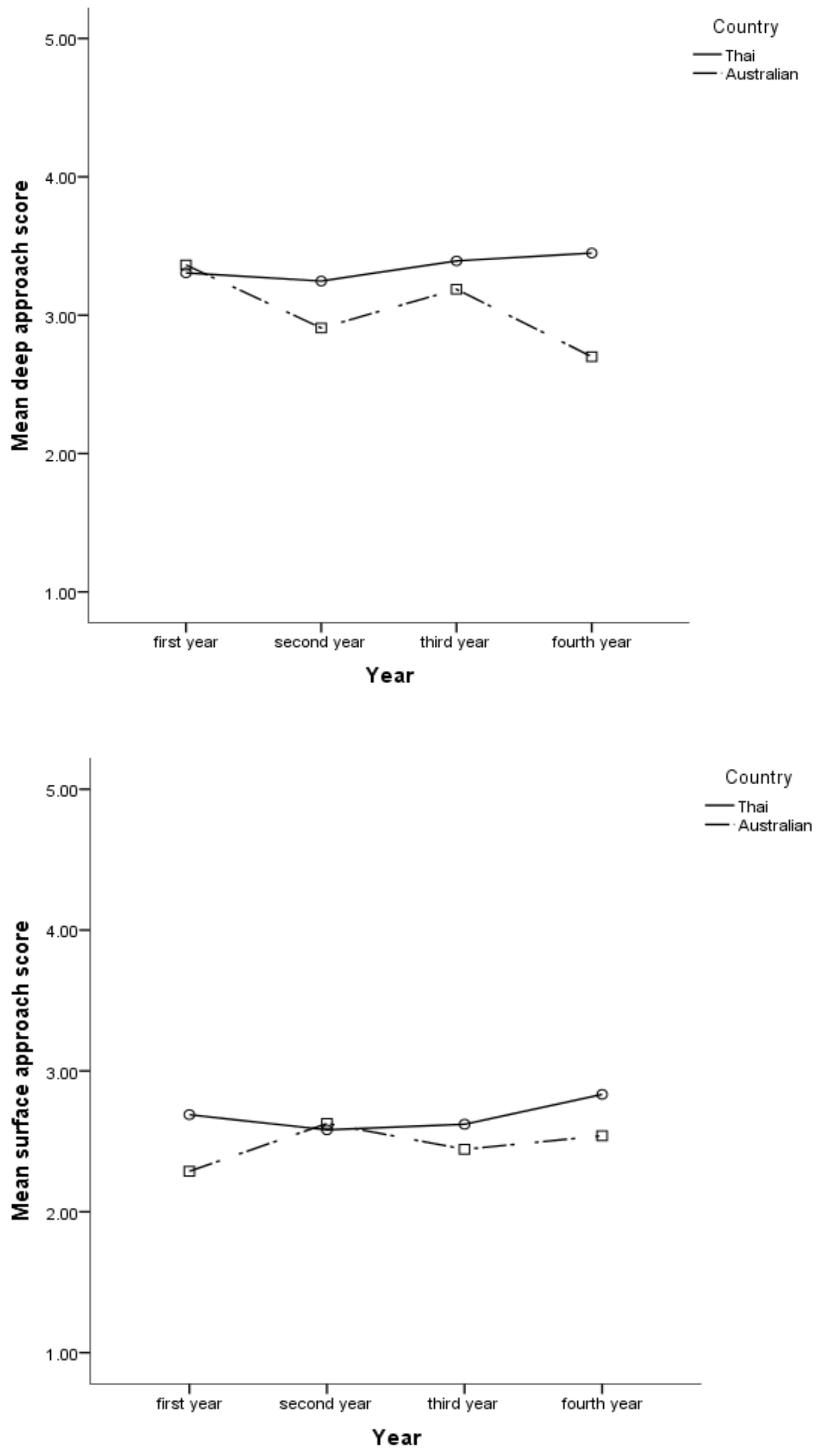


Figure 1. Mean deep and surface approach scores by Country and Year Level

Estimated Marginal Means of Task goal orientation

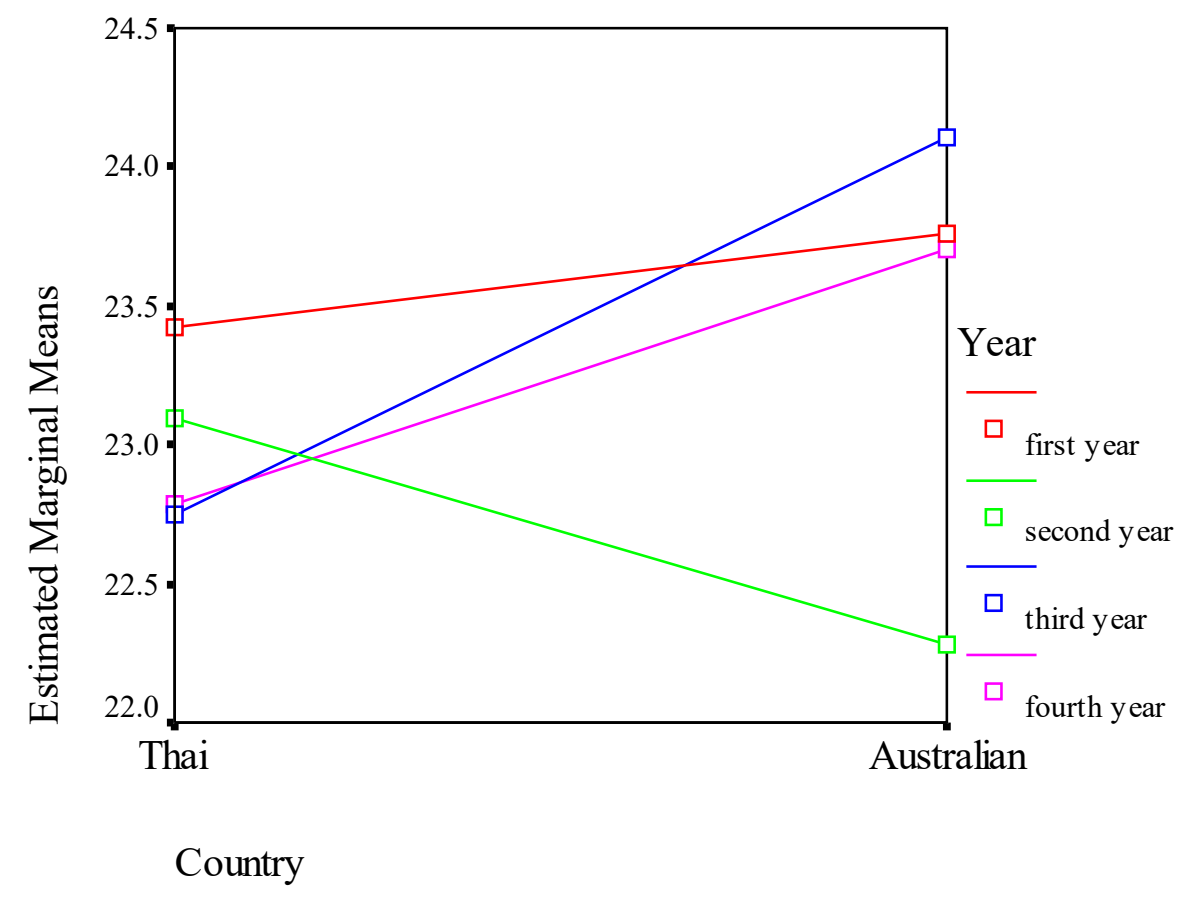

Figure 2. Interaction of Country $x$ Year of study on task goal orientation 


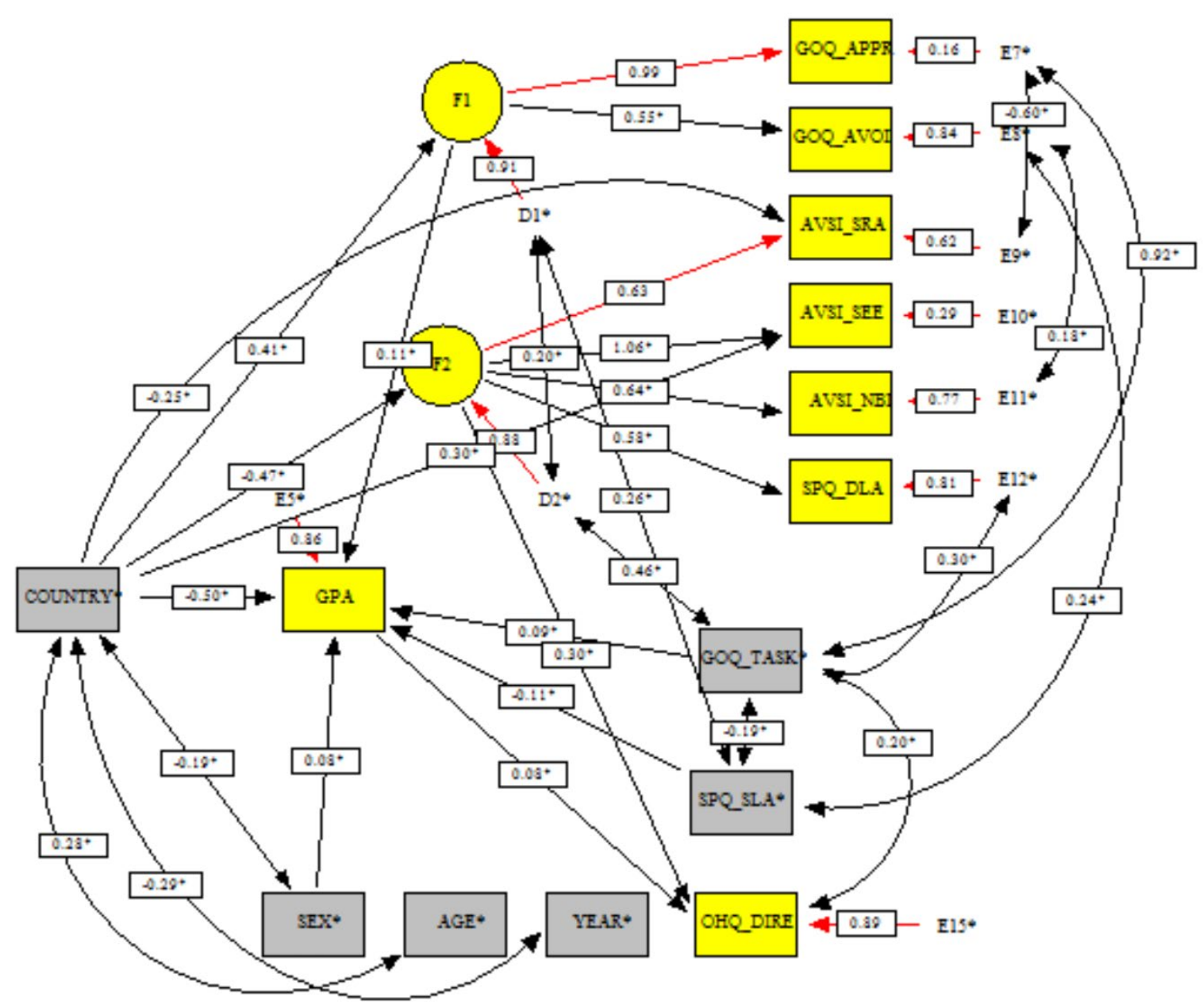

Figure 3. Predictors of GPA including Country, Goal Orientation, Academic Volitional Strategies, Psychological Wellbeing 